US Army Corps

of Engineers .

Prepared for the U.S. Army Corps of Engineers, Portland District,

under an Interagency Agreement with the U.S. Department of Energy

Contract DE-AC05-76RL01830

\title{
The Efficacy of
}

Ultraviolet Radiation for

Sterilizing Tools Used for Surgically

Implanting Transmitters into Fish

\section{Draft Final Report}

$\begin{array}{ll}\text { RW Walker } & \text { ME Gay } \\ \text { LM Markillie } & \text { CM Woodley } \\ \text { AH Colotelo } & \text { RS Brown }\end{array}$

February 2012

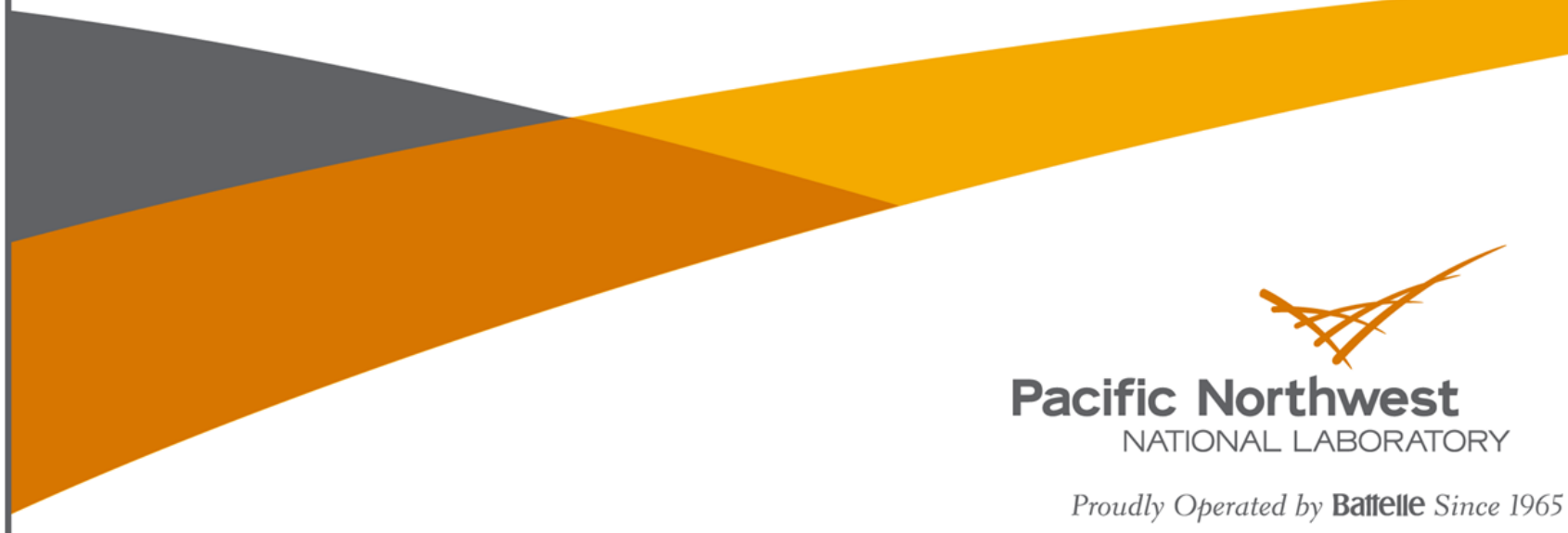




\title{
DISCLAIMER
}

This report was prepared as an account of work sponsored by an agency of the United States Government. Neither the United States Government nor any agency thereof, nor Battelle Memorial Institute, nor any of their employees, makes any warranty, express or implied, or assumes any legal liability or responsibility for the accuracy, completeness, or usefulness of any information, apparatus, product, or process disclosed, or represents that its use would not infringe privately owned rights. Reference herein to any specific commercial product, process, or service by trade name, trademark, manufacturer, or otherwise does not necessarily constitute or imply its endorsement, recommendation, or favoring by the United States Government or any agency thereof, or Battelle Memorial Institute. The views and opinions of authors expressed herein do not necessarily state or reflect those of the United States Government or any agency thereof.

\author{
PACIFIC NORTHWEST NATIONAL LABORATORY \\ operated by \\ BATTELLE \\ for the \\ UNITED STATES DEPARTMENT OF ENERGY \\ under Contract DE-AC05-76RL01830
}

Printed in the United States of America
Available to DOE and DOE contractors from the Office of Scientific and Technical Information,
P.O. Box 62, Oak Ridge, TN 37831-0062;
ph: (865) 576-8401
fax: $(865)$ 576-5728
email: reports@adonis.osti.gov
Available to the public from the National Technical Information Service
5301 Shawnee Rd., Alexandria, VA 22312
ph: (800) 553-NTIS (6847)
email: orders@ntis.gov <http://www.ntis.gov/about/form.aspx>
Online ordering: http://www.ntis.gov

This document was printed on recycled paper. 


\section{The Efficacy of Ultraviolet Radiation for Sterilizing Tools Used for Surgically Implanting Transmitters into Fish}

\section{Draft Final Report}

$\begin{array}{ll}\text { RW Walker } & \text { ME Gay } \\ \text { LM Markillie } & \text { CW Woodley } \\ \text { AH Colotelo } & \text { RS Brown }\end{array}$

February 2012

Prepared for

the U.S. Army Corps of Engineers, Portland District, under an Interagency Agreement with the U.S. Department of Energy Contract DE-AC05-76RL01830

Pacific Northwest National Laboratory

Richland, Washington 99352 



\section{Summary}

Telemetry is frequently used to examine the behavior of fish, and the transmitters used are normally surgically implanted into the coelomic cavity of fish. Implantation requires the use of surgical tools such as scalpels, forceps, needle holders, and sutures. When fish are implanted consecutively, as in large telemetry studies, it is common for surgical tools to be sterilized or, at minimum, disinfected between each use so that pathogens that may be present are not spread among fish. Autoclaving tools can take over an hour; chemical sterilants or disinfectants can be harmful to both humans and fish, and their effectiveness is variable. Ultraviolet (UV) radiation is commonly used to disinfect water in aquaculture facilities; however, this technology has not been widely used to sterilize tools for surgical implantation of transmitters in fish.

To determine its efficacy for this application, Pacific Northwest National Laboratory researchers used UV radiation to disinfect surgical tools (i.e., forceps, needle holder, stab scalpel, and suture) exposed to one of four aquatic organisms that typically lead to negative health issues for salmonids. These organisms included Aeromonas salmonicida, Flavobacterium psychrophilum, Renibacterium salmoninarum, and Saprolegnia parasitica causative agents of furunculosis, coldwater disease, bacterial kidney disease, and saprolegniasis (water mold), respectively.

Three experiments were conducted to address the question of UV efficacy. In the first experiment, forceps were exposed to the three bacteria by dipping them into a confluent suspension of three varying concentrations (i.e., low, medium, high). After exposure to the bacterial culture, tools were placed into a mobile Millipore UV sterilization apparatus. The tools were then exposed for three different time periods $-2,5$, or 15 min. With the exception that we were not able to grow $R$. salmoninarum on the positive controls at low and medium concentrations and thus cannot interpret whether UV radiation was the reason for no growth on the forceps in those tests, UV radiation exposures of 2, 5, and 15 min were effective at killing all three bacteria on forceps at the highest bacteria concentrations.

In the second experiment, stab scalpels, sutures, and needle holders were exposed to A. salmonicida using the same methodology as used in Experiment 1. UV radiation exposure at 5 and 15 min was effective at killing $A$. salmonicida on stab scalpels and sutures but not needle holders.

In the third experiment, $S$. parasitica, a water mold, was tested using an agar plate method and forceps-pinch method. However, a lack of growth on one of the three sham tests in the forceps-pinch portion of this study suggests that caution be used in interpreting these findings.

Collectively this study shows that UV radiation appears to provide a quick alternative disinfection technique to chemical disinfectants (e.g., ethanol) for some surgical tools that is less harmful to both humans and fish while not producing chemical waste. However, we do not recommend using this method for tools such as needle holders having overlapping parts or other structures that cannot be exposed directly to UV radiation. 



\section{Acknowledgments}

This study was funded by the U.S. Army Corps of Engineers (USACE), Portland District. The authors thank Brad Eppard of the USACE for his commitment, assistance, and oversight. With appreciation, we acknowledge the technical contributions to the project made by the following people from the Pacific Northwest National Laboratory: Amoret Bunn, Kate Deters, David Geist, Gayle Dirkes, Jill Janak, Andy LeBarge, Tim Linley, Ann Miracle, Brett Pflugrath, and John Stephenson. Editing was conducted by Andrea Currie. Pacific Northwest National Laboratory is operated by Battelle for the U.S. Department of Energy under Contract DE-AC05-76RL01830. 



\section{Acronyms and Abbreviations}

$\begin{array}{ll}\text { ATCC } & \text { American Type Culture Collection } \\ \text { BKD } & \text { bacterial kidney disease } \\ \text { CFU } & \text { colony-forming unit(s) } \\ \text { cm } & \text { centimeter(s) } \\ \text { DNA } & \text { deoxyribonucleic acid } \\ \text { d } & \text { day(s) } \\ \text { EPA } & \text { U.S. Environmental Protection Agency } \\ \text { FDA } & \text { U.S. Food and Drug Administration } \\ \text { min } & \text { minute(s) } \\ \text { mJ } & \text { millijoule(s) } \\ \mu L & \text { microliter(s) } \\ \text { mL } & \text { milliliter(s) } \\ \text { mm } & \text { millimeter(s) } \\ \text { mW } & \text { milliwatt(s) } \\ \text { NCR } & \text { National Research Council } \\ \mathrm{nm} & \text { nanometer(s) } \\ \text { OD } & \text { optical density } \\ \text { s } & \text { second(s) } \\ \text { SAL } & \text { sterility assurance level } \\ \text { SD } & \text { standard deviation } \\ \text { UV } & \text { ultraviolet } \\ & \end{array}$





\section{Contents}

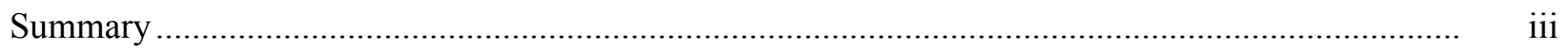

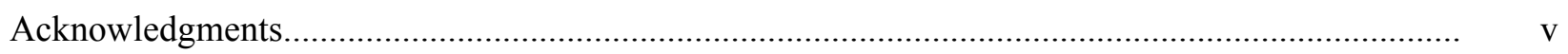

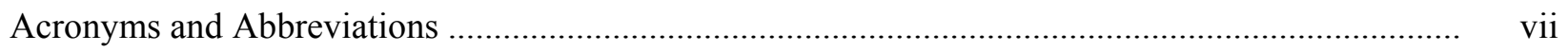

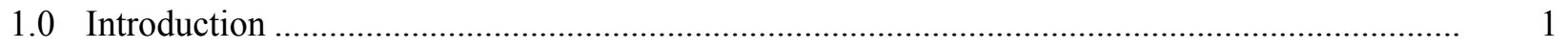

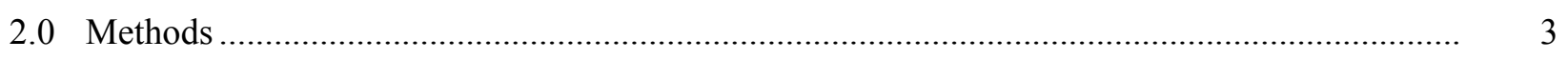

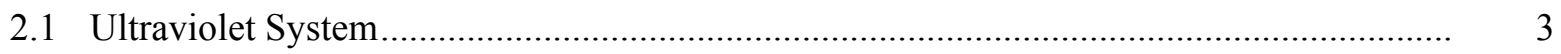

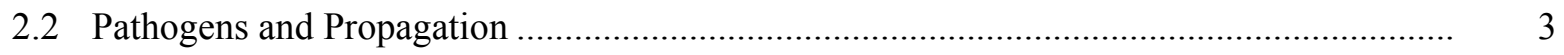

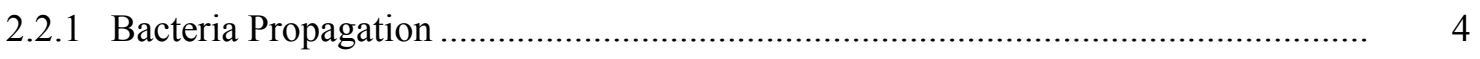

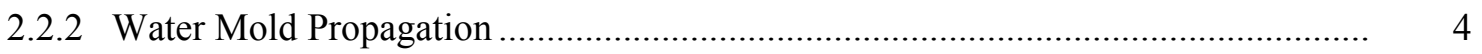

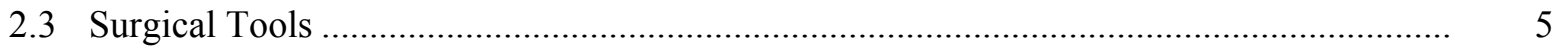

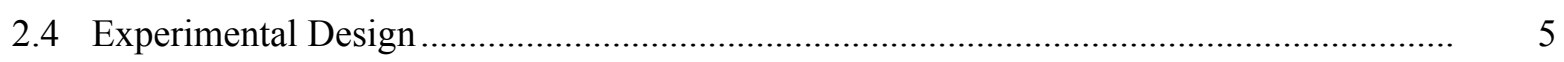

2.4.1 Bacterial Exposure to Ultraviolet Radiation ....................................................... 5

2.4.2 Water Mold Exposure to Ultraviolet Radiation …….............................................. 8

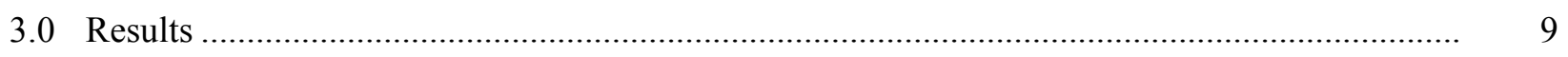

3.1 Ultraviolet System Radiometer Measurements ............................................................... 9

3.2 Experiment 1 - Forceps Exposed to Three Bacteria ........................................................ 9

3.3 Experiment 2 - Three Surgical Tools Exposed to A. salmonicida ..................................... 11

3.4 Experiment 3 - Water Mold Testing ......................................................................... 12

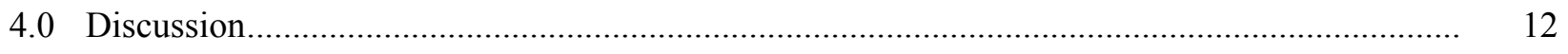

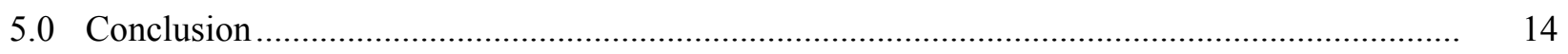

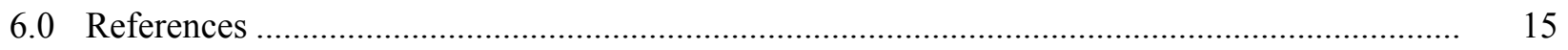

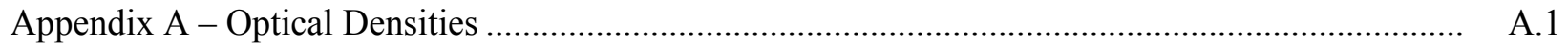

Appendix B - Ultraviolet Dose Measurements ..................................................................... B. 1 


\section{Figures}

1 Millipore ultraviolet sterilizer.

2 A cornmeal agar plate with $S$. parasitica growth and a cornmeal agar plate lacking any growth

3 Surgical tools used in testing efficacy of UV radiation exposure

\section{Tables}

1 Experimental design showing three test replicates for each combination of UV radiation exposure time and bacteria concentration

2 Colony-forming units for low, medium, and high concentrations of bacteria

3 The presence/absence of A. salmonicida, F. psychrophilum, and $R$. salmoninarum applied to forceps treated with UV radiation for four different durations

4 Presence/absence of growth of the A salmonicida applied to stab scalpels, sutures, and needle holders and exposed to UV radiation for $0,2,5$, or $15 \mathrm{~min}$

5 The presence/absence of the water mold applied to the agar plates and forceps exposed to UV radiation for four different durations and incubated for $10 \mathrm{~d}$........ 


\subsection{Introduction}

Juvenile salmonids are often surgically implanted with transmitters to monitor behavior and survival during seaward migrations. Researchers conducting telemetry studies assume that tagged fish are representative of nontagged fish (Baras and Lagardére 1995, Bégout Anras et al. 1998). The presence of telemetry tags and the tagging process may influence growth, behavior, and survival, resulting in tagged fish not being representative of the population, potentially leading to biases in these studies (Bridger and Booth 2003; Brown et al. 2010). In addition, the surgical process can expose juvenile salmonids to harmful aquatic diseases, which can also result in survival rates or behavior that is different from that of the untagged population.

To minimize the risk of transmitting pathogens among fish when surgically implanting transmitters, aseptic protocols must be in place to reduce or eliminate harmful organisms on surgical tools. Ideally, the protocols would include the use of a sterile set of tools for each fish. However, when large numbers of fish are implanted (as is common in the Columbia River basin; McMichael et al. 2010), providing a separate tool set for each implantation can be a logistical challenge. A relatively rapid and inexpensive technique is needed for disinfecting or sterilizing surgical tools between surgical implantations to prevent transmission of aquatic diseases.

Sterilization, by definition, means that all microorganisms, endospores, and viruses are destroyed (Gurevich et al. 1996). Sterilization of surgical tools can be accomplished by steam, dry heat, chemical vapor, or immersion in chemical sterilants for 6 to $10 \mathrm{~h}$ (Gurevich et al. 1996). For example, autoclaves utilize high pressure and steam for sterilization and are commonly used in laboratories and hospitals to sterilize tools because of their efficacy at inactivating viruses and spores that can be harder to inactivate than vegetative bacteria (Liltved et al. 1995). The disadvantage of autoclaves is that they are often expensive, large, and heavy (although tabletop units are portable) and cannot be used with heat-labile items. In addition, a complete autoclave cycle can take approximately $1 \mathrm{~h}$ to run, which is not always conducive in large applications or a field study. Nearly all available sterilization techniques are time consuming and may, in some circumstances, compromise the study objectives (e.g., telemetry studies during defined fish migration periods) or the health and wellbeing of the fish (e.g., excessive surgical times that result in extra handling of fish). As such, there is a need to use adequate disease management within reasonable time periods; currently available sterilization techniques may not always provide that option.

Disinfection, which is the elimination of most disease-causing microorganisms or viruses but not necessarily spores, is a more reasonable option because it can be done in a relatively short time (e.g., 20 -min submersion of tools in 70\% ethanol; Rutala et al. 2008). Different levels of disinfection can be accomplished using liquid chemicals or wet pasteurization, depending on the disinfectant used and exposure time. A high-level disinfectant will kill all microorganisms except a high level of bacterial spores, while a low level-disinfectant will kill most vegetative bacteria, some fungi, and some viruses (Rutala et al. 2008). Ethanol and isopropyl alcohol, commonly used in the Columbia River basin as disinfectants, are effective for killing only vegetative bacteria and viruses but not spores (Rutala et al. 2008). Although the use of chemicals (e.g., ethanol, hydrogen peroxide, Virkon $\AA$, chlorohexidine) is effective for the disinfection of surgical tools (Wagner et al. 2011), some products commonly used may pose threats to the health of both tagged fish and surgeons. Further, the use of most chemical disinfectants results in waste that must be disposed of properly, which can be very expensive (although 
evaporation of small amounts of chemical disinfectants like alcohol may be possible). Thus, there is a need to identify other disinfection techniques for use on surgical tools used for performing surgeries on fish.

Ultraviolet (UV) radiation is generally used for the disinfection of water in aquaculture and wastewater facilities because it does not produce any known toxic residuals or byproducts that may pose a risk to people or fish (Giese and Darby 2000; Liltved and Landfald 2000; Summerfelt 2003; Bohrerova et al. 2008). UV radiation is also used to improve air quality within buildings (Martin et al. 2008). Although intense UV radiation can be harmful to operators if used improperly, proper equipment and use can mitigate impacts. However, despite its wide use, there is a lack of information available on the efficacy of UV radiation for disinfecting or sterilizing surgical tools.

The UV spectrum is commonly subdivided into three sections: UVA (wavelengths of $400 \mathrm{~nm}$ to $315 \mathrm{~nm}$ ), UVB (315 nm to $280 \mathrm{~nm}$ ), and UVC (280 nm to $200 \mathrm{~nm})$. UVC radiation denatures the DNA of microorganisms, which have a high absorbance of the UV spectrum at $254 \mathrm{~nm}$. Denaturing is caused by the formation of pyrimidine dimers, resulting in the inactivation of the bacterium by blocking DNA replication (Giese and Darby 2000; Summerfelt 2003; Liltved et al. 2006). Although the entire UV spectrum has been known to kill or inactivate many microorganisms, some researchers suggest that a wavelength of $254 \mathrm{~nm}$ (UVC) is most effective (Summerfelt 2003; Sharrer et al. 2005; Martin et al. 2008). Thus, Summerfelt (2003) suggests that monochromatic UVC radiation is the industry standard. The type of radiation varies not only with the wavelength of the UV light source but also with the quantity of the energy transmitted (in millijoules per square centimeter $\left[\mathrm{mJ} / \mathrm{cm}^{2}\right]$; Summerfelt 2003). The dosages required for inactivation of pathogens vary. However, some research suggests that the most common bacteria and viruses can be inactivated by UV doses of $30 \mathrm{~mJ} / \mathrm{cm}^{2}$ at a wavelength of $254 \mathrm{~nm}$ (Wedemeyer 1996); for example, infectious hematopoietic necrosis virus (IHNV) is inactivated at $2 \mathrm{~mJ} / \mathrm{cm}^{2}$ (Wedemeyer 1996). Conversely, mold and fungi require greater exposures at certain life stages; inhibition of Saprolegnia spp. hyphae growth requires $230 \mathrm{~mJ} / \mathrm{cm}^{2}$ (Wedemeyer 1996).

The objective of this study was to test the efficacy of UV radiation (using a wavelength of $254 \mathrm{~nm}$ ) as a disinfectant of common surgical tools that were exposed to the bacteria and water mold that cause several common diseases of juvenile salmonids in the Columbia River basin. In our first experiment, we exposed forceps to Aeromonas salmonicida, Flavobacterium psychrophilum, and Renibacterium salmoninarum, which are the causative agents of furunculosis, coldwater disease, and bacterial kidney disease, respectively. In the second experiment, we expanded the number of surgical instruments to include stab scalpels, needle holders, and suture material and exposed them to $A$. salmonicida (furunculosis). Finally, in our third experiment, we explored whether UV radiation was effective at killing the common water mold (Saprolegnia parasitica) on an agar plate and on surgical forceps. The pathogens used in this study were chosen because they are found in the Columbia and Snake rivers and represent gram negative bacteria, gram positive bacteria, and an oomycete, a fungus-like microorganism. The tools chosen for the experiment were made of various materials (i.e., stainless steel, plastic, and monofilament thread) and various surfaces (i.e., smooth, grooved, and overlapping) that are commonly used in studies where fish undergo surgical implantation of transmitters.

In all cases, we attempted to utilize surgical tools and techniques common to a broad range of fisheries studies. As such, we believe the results of our study will be of interest to fisheries researchers and managers, not only in the Columbia River basin but in any area where surgical procedures are used on fish potentially exposed to these diseases. 


\subsection{Methods}

\subsection{Ultraviolet System}

The UV system used in testing was a Millipore UV sterilizer (Catalog No. XX6370000, Billerica, Massachusetts) with four 253.7-nm wavelength Sylvania germicidal UV lamps (Part No. G8T5; Figure 1A). Each bulb has two anodized aluminum reflectors so that there is maximum exposure of the tools to the UV light (Figure 1B). The system is fully enclosed by a fiberglass case (Figure 1C) to prevent exposure of UV radiation to operators and also is equipped with a safety switch that prevents the lamps from energizing while the case is open. The UV system was originally designed to prevent organism carryover on funnels and as an economical alternative to autoclaving (www.millipore.com). A calibrated radiometer (UVICURE Plus II, Serial No. 15405, EIT Inc., Sterling, Virginia) was placed in the same location in the UV system during each exposure to quantify the power output (Figure 1A).

During the study, it became apparent that modifications to the UV system were needed to increase the area where tools would be exposed to all four UV radiation lamps. Part of the blue aluminum plate (Figure 1B) was removed and replaced with an optical-grade fused quartz $(482.6 \mathrm{~mm}$ long $\times 254.0 \mathrm{~mm}$ wide $\times 6.4 \mathrm{~mm}$ thick; Technical Glass Products, Inc., Painesville, Ohio). The glass used provided maximum transmittance of the UV radiation, while standard glass or acrylic will absorb a considerable portion of the UV radiation. The average transmittance of a 10-mm-thick piece of fused quartz glass for UV light at $254 \mathrm{~nm}$ is approximately $90 \%$ (Technical Glass Products, Inc.; http://www.technicalglass.com/).

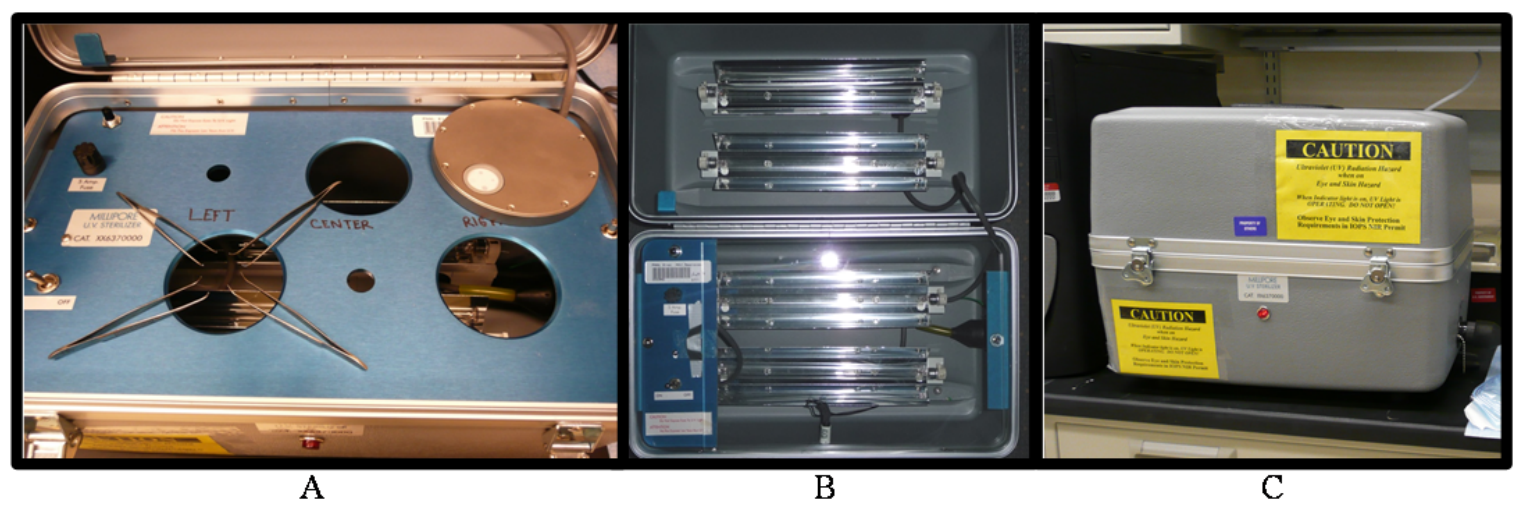

Figure 1. Millipore ultraviolet sterilizer. (A) UV system interior with forceps placed for treatment. The radiometer is located in the top right-hand corner of the picture. (B) UV system modified by replacing most of the blue center plate with a fused quartz glass that had minimal UV absorption. (C) Exterior of the UV system.

\subsection{Pathogens and Propagation}

To determine the effectiveness of UV radiation at killing a wide range of microorganisms, three different bacteria and one oomycete were used in the tests. Microorganisms were acquired from American Type Culture Collection (ATCC, Rockville, Maryland). The three bacteria used were Aeromonas salmonicida subspecies achromogenes (ATCC 10801), Flavobacterium psychrophilum 
(ATCC 49510), and Renibacterium salmoninarum (ATCC 33209) and are the causative agents of furunculosis, coldwater disease, and bacterial kidney disease (BKD), respectively. The oomycete (water mold) was Saprolegnia parasitica (ATCC 11393). All microorganisms were originally propagated following ATCC product information sheets provided with cultures.

\subsubsection{Bacteria Propagation}

Bacterial microorganisms were propagated to test the efficacy of UV radiation to disinfect forceps after exposure to A. salmonicida, F. psychrophilum, and $R$. salmoninarum and to disinfect stab scalpels, sutures, and needle holders exposed to A. salmonicida. This was done by taking a single colony from the solid media and inoculating $1 \mathrm{~mL}$ of appropriate liquid media in a 5 -mL Falcon culture tube (Becton Dickinson, Franklin Lakes, New Jersey). The inoculated broth was allowed to incubate to produce a larger biomass of microorganisms. A. salmonicida, F. psychrophilum, and $R$. salmoninarum were incubated for 2,10 , and $20 \mathrm{~d}$, respectively.

After the incubation, the cultures were serially diluted to attain three bacterial concentrations-low (1:100,000 dilution), medium $(1: 1,000)$, and high (1:10). The numbers of colony-forming units $(\mathrm{CFU}) / \mathrm{mL}$ found in each suspension were quantified by serial dilution in appropriate media and bead streaked on agar plates specific for each organism. After the agar plates were incubated (the length of time described above), colonies were counted and their densities of CFU were determined ([number of $\mathrm{CFU} /($ volume plated $(\mathrm{mL}) \times$ total dilution used]; Table 2$)$.

\subsubsection{Water Mold Propagation}

The original culture of water mold was propagated to determine the efficacy of UV radiation to disinfect forceps exposed to water mold. This was done in deionized water and plated out on cornmeal agar plates. Once the water mold grew on the agar, a cube $\left(\sim 5 \mathrm{~mm}^{3}\right)$ of agar with growing water mold was transferred to a fresh agar plate weekly until needed for testing. Growth was easily seen on the cornmeal plates by observing the hyphae (Figure 2).

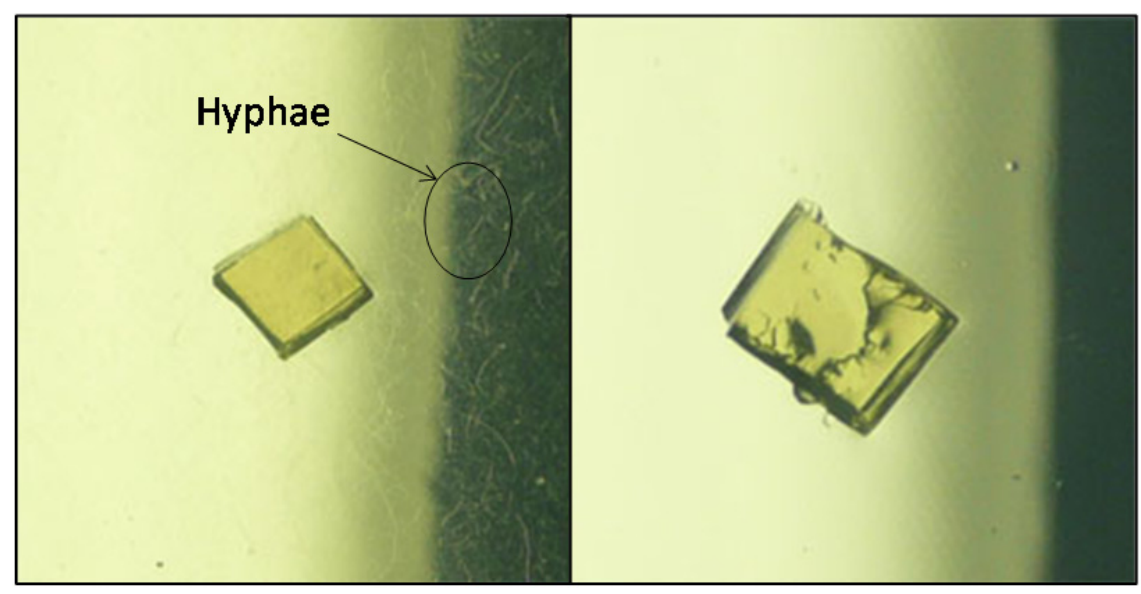

Figure 2. A cornmeal agar plate with $S$. parasitica growth (left, indicated by translucent strands) and a cornmeal agar plate lacking any growth (right). 


\subsection{Surgical Tools}

Four commonly used surgical tools were tested in this study-needle holders, forceps, monofilament sutures, and stab scalpels. The needle holders (Model 12002-11, Fine Science Tools Inc., Heidelberg, Germany) were $11 \mathrm{~cm}$ long with a cutting edge and a 1.5-mm-wide serrated tip (Figure 3A). The forceps (Fine Science Tools Inc.; Figure 3B) were $10 \mathrm{~cm}$ long; the tip of the forceps for models 11052-10 and 11152-10 were serrated and measured $0.8 \mathrm{~mm}$ in length $\times 0.7 \mathrm{~mm}$ in width and $0.5 \mathrm{~mm}$ in length $\times$ $0.5 \mathrm{~mm}$ in width, respectively. Monocryl monofilament absorbable sutures with an RB-1 needle (size 5-0 monofilament, Ethicon, San Angelo, Texas) were tested (Figure 3C). Stab scalpels (Model BD Beaver Micro-Sharp Blades, Becton, Dickinson and Company, Franklin Lakes, New Jersey) were $3 \mathrm{~mm}$ long and had a cutting angle of $15^{\circ}$ (Figure 3D).

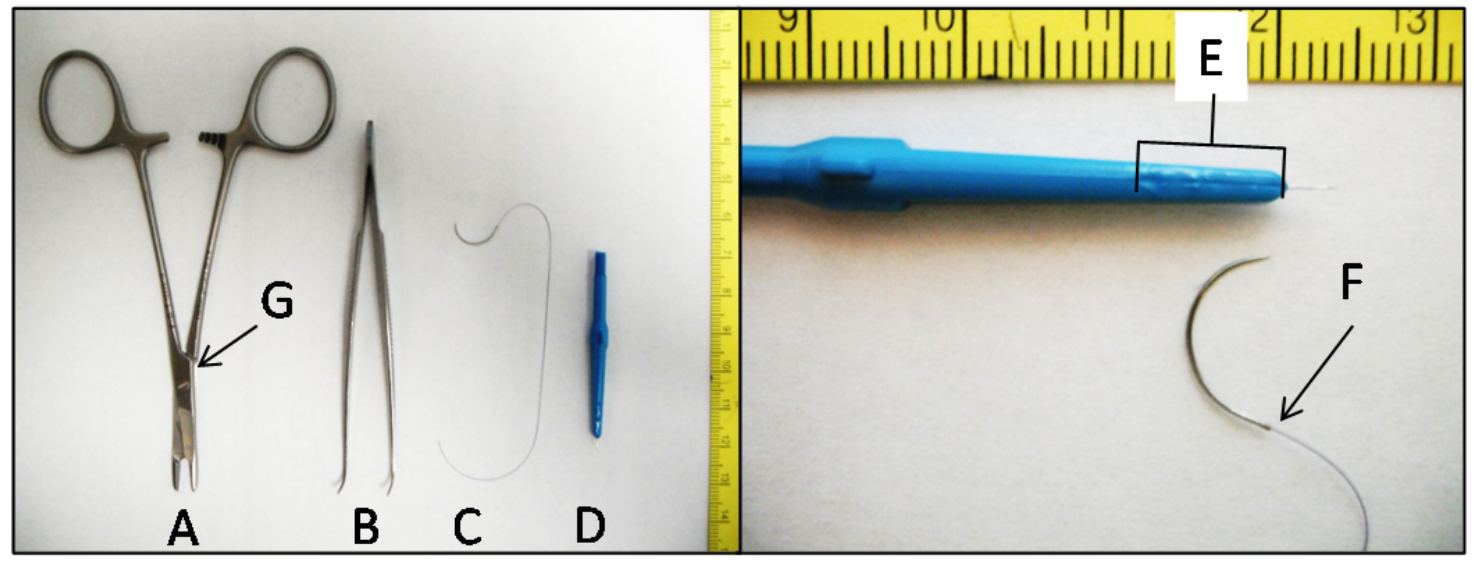

Figure 3. Surgical tools used in testing efficacy of UV radiation exposure. (A) needle holder, (B) forceps, (C) suture, and (D) stab scalpel. The stab scalpel had an area of concern (E) in regard to UV radiation penetration at the point where the blade was inserted into the plastic portion of the stab scalpel. The suture also had an area of concern (F) where the needle and monofilament were swaged together. The needle holder had an area of concern $(G)$ where the two halves overlapped.

\subsection{Experimental Design}

Three experiments were conducted to assess the efficacy of using UV radiation to eliminate pathogens from surgical instruments:

\subsubsection{Bacterial Exposure to Ultraviolet Radiation}

Experiments 1 and 2 had positive and negative controls. Positive controls (also called sham tests) consisted of exposing the tools to the pathogen but not to the UV, and were used to demonstrate that the pathogen would grow on specific tools at the pathogen concentrations used in the experiments. A positive result for the positive control verified that if we observed a negative response from the UV treatment, we could conclude that the UV was effective at reducing the population of the pathogen at that concentration. However, if the positive control failed to produce the pathogen, we did not use those results in our analysis because we would not be able to conclude that the UV was the result of the 
negative response. Negative controls consisted of not exposing the tools to the pathogen but exposing them to the UV radiation. The lack of positive growth on a negative control demonstrated that the UV system did not introduce the pathogen to the tool (e.g., cross contamination from an earlier study). If bacteria growth was observed on the negative control, the bacteria were incubated on and grown on agar plates until we could identify characteristics that were consistent with the experimental bacteria or, conversely, from environmental contamination.

Experiments 1 and 2 involving the bacteria (Table 1) consisted of four durations of UV exposure (0 [sham], 2, 5, and $15 \mathrm{~min}$ ) and four bacteria concentrations (none [negative control], low, medium, and high); the bacteria concentration varied based on the pathogen (Table 2). Three replicates were used for each combination of UV duration and bacteria concentration. The one exception was $R$. salmoninarum, for which five replicates were used because the long incubation period (20-37d) increased the chance for environmental contamination of the treatments.

Table 1. Experimental design showing three test replicates for each combination of UV radiation exposure time and bacteria concentration. Tests involving $R$. salmoninarum included five test replicates. "None" represents the "Negative" control. Concentrations for "Low," "Medium," and "High" are given in Table 2.

\begin{tabular}{lcccc}
\hline & \multicolumn{2}{c}{ Bacteria concentration } \\
\hline $\begin{array}{l}\text { UV radiation } \\
\text { duration }\end{array}$ & $\begin{array}{c}\text { None } \\
\text { (negative control) }\end{array}$ & Low & Medium & High \\
\hline 0 min (sham) & - & 3 & 3 & 3 \\
$2 \min$ & 3 & 3 & 3 & 3 \\
5 min & 3 & 3 & 3 & 3 \\
15 min & 3 & 3 & 3 & 3 \\
\hline
\end{tabular}


Table 2. Colony-forming units $(\mathrm{CFU} / \mathrm{mL})$ for low, medium, and high concentrations of bacteria. The density of colony-forming units is shown for each of the two experiments involving bacteria for the different surgical tools.

\begin{tabular}{lcccc}
\hline & \multicolumn{4}{c}{ Bacteria concentration $(\mathrm{CFU} / \mathrm{mL})$} \\
\hline Pathogen & Tool & Low & Medium & High \\
\hline \multicolumn{2}{c}{ Experiment 1} \\
Aeromonas salmonicida & & $1.79 \times 10^{7}$ & $1.79 \times 10^{9}$ & $1.79 \times 10^{11}$ \\
Flavobacterium psychrophilum & Forceps & $5.83 \times 10^{7}$ & $5.83 \times 10^{9}$ & $5.83 \times 10^{11}$ \\
Renibacterium salmoninarum & & $6.28 \times 10^{8}$ & $6.28 \times 10^{10}$ & $6.28 \times 10^{12}$ \\
\hline & Experiment 2 & & \\
\hline & Suture & $4.98 \times 10^{6}$ & $4.98 \times 10^{8}$ & $4.98 \times 10^{10}$ \\
Aeromonas salmonicida & Stab scalpel & $5.86 \times 10^{7}$ & $5.86 \times 10^{9}$ & $5.86 \times 10^{11}$ \\
& Needle holder & $1.43 \times 10^{4}$ & $1.43 \times 10^{6}$ & $1.43 \times 10^{8}$ \\
\hline
\end{tabular}

\subsubsection{Experiment 1 - Forceps Exposed to Three Bacteria}

The first experiment involved the exposure of forceps to the three bacteria (A. salmonicida, $F$. psychrophilum, and $R$. salmoninarum) and then exposing the instruments to UV radiation for different lengths of time to test the hypothesis that UV radiation would be a viable option for disinfection. Autoclaved forceps were exposed to each concentration of bacteria by dipping the tips about $5 \mathrm{~mm}$ into the confluent suspension for $5 \mathrm{~s}$. For each group (i.e., forceps exposed to none, low, medium, and high concentration of bacteria), the forceps were placed into the UV system immediately after dipping and then were exposed to UV radiation for a duration of 0 (sham), 2, 5, or $15 \mathrm{~min}$. The forceps were placed over one of the three large holes in the UV sterilizer platform (Figure 1A). The order of exposure time for each test was chosen randomly. After exposure, forceps were taken out of the UV sterilizer and furthest extending $10 \mathrm{~mm}$ of the tips were rinsed with $5 \mathrm{~mL}$ of the appropriate sterile medium into a culture tube. Sham controls were dipped in the same way as the UV-treated forceps but were never placed into the UV system. Instead, immediately after the sham control forceps were dipped, they were rinsed in the same way as the UV-treated forceps. The negative control forceps were handled in the same way as the UV-treated forceps except that they were not dipped in the bacterial culture. Following the appropriate incubation period as described above, optical densities of the culture tubes were measured and samples were visually checked for growth. The optical densities were used only as a determination of presence $\left(\mathrm{OD}_{600}>0.00\right)$ or absence $\left(\mathrm{OD}_{600}=0.00\right)$ of growth. Measured values for the optical densities are reported in Appendix A. 


\subsubsection{Experiment 2 - Three Surgical Tools Exposed to A. salmonicida}

Based on the results we observed using forceps and three bacteria in Experiment 1, further testing was conducted to examine the efficacy of UV radiation to disinfect other tools commonly used to surgically implant transmitters in fish: stab scalpels, 5-0 Monocryl monofilament sutures, and needle holders. This was done because microorganisms could possibly be shielded from UV radiation in areas on the tools where the UV light was not able to penetrate - for example, where the blade is inserted and epoxied into the plastic portion of the stab scalpel (Figure 3E), in the area where the suture needle is swaged to the monofilament thread (Figure 3F), and in the hinged area of the needle holders (Figure 3G). Stab scalpels, sutures, and needle holders were exposed to A. salmonicida using methods similar to those described above in Experiment 1. A. salmonicida was the only pathogen chosen for these tests because of the short duration needed to grow it successfully in the laboratory.

Prior to testing, stab scalpels and 5-0 monofilament absorbable sutures were new and sterile. Stab scalpels were submerged in the bacterial culture deep enough to cover the entire blade and the groove in the plastic portion of the stab scalpel $(12-15 \mathrm{~mm})$. After UV treatment, the stab scalpel was rinsed from just above the groove toward the blade. Sutures were exposed to the bacteria by being placed into the culture tube so that the needle (including the section where the thread is swaged onto the needle) and about $23 \mathrm{~mm}$ of the thread were submerged for at least $5 \mathrm{~s}$. The culture tube then was inverted so that the entire thread (127 $\mathrm{mm}$ total length) would also be exposed to the bacteria. The suture was laid out on the fused quartz plate so that there was not any overlap. Following UV radiation exposure, sutures were placed into a tube with $5 \mathrm{~mL}$ of sterile media using autoclaved needle holders and incubated for $5 \mathrm{~d}$ while the suture remained in the culture. Needle holders were autoclaved prior to testing. To maximize the likelihood that microbes would remain in areas that were hard for UV radiation to reach, $1 \mathrm{~mL}$ of the culture (i.e., low, medium, high concentrations) was pipetted onto the hinge area (joint) of the needle holder. The culture was not reused among needle holders tested. Immediately after exposure to the culture, needle holders were placed in the UV system for the prescribed amount of time (i.e., 0 [sham], 2, 5, $15 \mathrm{~min}$ ). Growth for all tools was quantified as described for Experiment 1.

\subsubsection{Water Mold Exposure to Ultraviolet Radiation}

We tested water mold by exposing three cornmeal agar plates with the pathogen, then exposing the agar plates to one of the prescribed UV radiation durations (i.e., 0 [sham], 2, 5, or $15 \mathrm{~min}$ ). No negative control was used for this portion of the experiment. The second portion of the water mold experiment was similar to Experiment 1 (forceps exposed to three bacteria) except that the forceps were exposed to the pathogen on solid cornmeal agar plates, resulting in similar pathogen exposure concentrations between all forceps for each UV radiation exposure duration.

\subsubsection{Experiment 3 - Water Mold Testing}

The second part of our hypothesis was to test the effectiveness of UV radiation to kill the water mold S. parasitica, which was tested in two different ways. The first test used freshly plated water mold on cornmeal agar. The water mold was propagated on solid cornmeal agar for $5 \mathrm{~d}$. A cube of agar $\left(\sim 5 \mathrm{~mm}^{3}\right)$ was then removed from the 5 -d culture and placed on a sterile cornmeal agar plate $(n=3)$. Immediately after being placed on the agar plates, the plates were placed in the UV sterilizer and then exposed to $\mathrm{UV}$ radiation for 2, 5, or $15 \mathrm{~min}$. An additional three plates representing a sham control were inoculated 
and not exposed to UV radiation. A negative control was not included in this portion of the study because the likelihood of environmental contamination was minimal. Following the UV radiation exposure, the plates were incubated at room temperature for $5 \mathrm{~d}$ to determine if there was any new mycelium growth.

The second test in Experiment 3 used autoclaved forceps and a cornmeal agar plate with water mold that had been incubated for $5 \mathrm{~d}$. Three replicates were used for each group exposed to UV radiation. The forceps tips $(\sim 5 \mathrm{~mm})$ were pushed into the agar with visible mycelium growth and closed. The forceps were immediately placed into the UV sterilizer for treatments of $0,2,5$, and $15 \mathrm{~min}$. After treatment in the UV sterilizer, about $10 \mathrm{~mm}$ of the forceps were rinsed with $5 \mathrm{~mL}$ of liquid cornmeal broth into sterile 14-mL Falcon culture tubes. A sham control was included in this portion of the study, in which forceps were exposed to the water mold using methods described above but were not exposed to UV radiation. Instead, the sham control was immediately rinsed after being exposed to the water mold. A negative control was used for UV radiation exposure treatment (i.e., 0, 2, 5, and $15 \mathrm{~min}$ ) and was handled in the same way as the UV radiation treated forceps except it was not exposed to water mold. Samples were then allowed to incubate at room temperature for $5 \mathrm{~d}$ and $10 \mathrm{~d}$ before they were examined for growth by visually comparing the positive controls and UV-treated samples. In this experiment, growth was not quantified using optical densities because the water mold that grew was attached to granules of cornmeal and not confluent within the liquid media.

\subsection{Results}

\subsection{Ultraviolet System Radiometer Measurements}

Dose measurements were consistent among tests. Mean ( \pm standard deviation) doses were 108.87 $( \pm 5.20), 319.63( \pm 17.51)$ and $1051.02( \pm 67.54) \mathrm{mJ} / \mathrm{cm}^{2}$ for the 2-min, 5-min, and 15-min exposures, respectively. Doses for each individual test are reported in Appendix B.

\subsection{Experiment 1 - Forceps Exposed to Three Bacteria}

We hypothesized that UV radiation would be effective at disinfecting forceps exposed to three bacteria. The UV sterilizer was effective for inactivating all three disease-causing bacteria applied to forceps (Table 3). Growth of A. salmonicida and F. psychrophilum was consistently negative for forceps exposed to all bacteria concentrations and then treated with the UV sterilizer. Growth of $R$. salmoninarum was negative for all high concentrations. However, because there was not any growth in four of the five medium-concentration sham controls or in all of the low-concentration sham controls, the results for medium and low UV radiation-treated samples were not included. One of five replicates of the negative control (15-min UV exposure test) for $R$. salmoninarum showed growth. The suspect sample was plated on agar, incubated, and grown for $7 \mathrm{~d}$. The growth was determined to not be $R$. salmoninarum, indicating that this growth was due to environmental contamination and not cross contamination of R. salmoninarum. 
Table 3. The presence/absence of A. salmonicida (furunculosis disease), F. psychrophilum (coldwater disease), and $R$. salmoninarum (bacterial kidney disease) applied to forceps treated with UV radiation for four different durations. The $(+)$ symbol represents growth in samples for each replicate of the test while the (-) represents no growth in samples for each replicate; the number of replicates for $R$. salmoninarum was 5 versus 3 for the other two bacteria.

\begin{tabular}{|c|c|c|c|c|}
\hline $\begin{array}{l}\text { UV radiation } \\
\text { duration }\end{array}$ & $\begin{array}{c}\text { Bacteria } \\
\text { concentration }\end{array}$ & A. salmonicida & F. psychrophilum & R. salmoninarum \\
\hline \multirow[t]{3}{*}{0 min (sham) } & Low & +++ & +++ & --- \\
\hline & Medium & +++ & +++ & +--- \\
\hline & High & +++ & +++ & +++++ \\
\hline \multirow[t]{4}{*}{$2 \mathrm{~min}$} & None & -- & -- & ---- \\
\hline & Low & -- & -- & $---\cdot$ \\
\hline & Medium & -- & -- & ---- \\
\hline & High & --- & -- & $---\cdot$ \\
\hline \multirow[t]{4}{*}{$5 \mathrm{~min}$} & None & --- & -- & $-\ldots$ \\
\hline & Low & --- & -- & $---\cdot$ \\
\hline & Medium & -- & -- & $-\ldots$ \\
\hline & High & --- & --- & ---- \\
\hline \multirow[t]{4}{*}{$15 \mathrm{~min}$} & None & --- & -- & +--- \\
\hline & Low & -- & -- & $-\cdots$ \\
\hline & Medium & --- & -- & ---- \\
\hline & High & --- & $--\cdot$ & $---\cdot$ \\
\hline
\end{tabular}




\subsection{Experiment 2 - Three Surgical Tools Exposed to A. salmonicida}

Ultraviolet radiation was effective for killing all densities of $A$. salmonicida on sutures, but results were variable for stab scalpels and needle holders (Table 4). However, for sutures, only two of the three low-concentration sham controls had growth. Growth of samples from stab scalpels was negative for all UV radiation treated samples except for one of the 2-min high-pathogen concentration samples, which had growth. UV-treated samples for needle holders exposed to medium and high levels of $A$. salmonicida had growth in all three replicates for all exposure durations tested.

Table 4. Presence/absence of growth of the $A$ salmonicida (furunculosis disease) applied to stab scalpels, sutures, and needle holders and exposed to UV radiation for $0,2,5$, or $15 \mathrm{~min}$. The $(+)$ symbol represents growth in samples for each replicate of the test; the $(-)$ represents no growth in samples. "None" represents the negative control.

\begin{tabular}{|c|c|c|c|c|}
\hline $\begin{array}{l}\text { UV radiation } \\
\text { duration }\end{array}$ & $\begin{array}{c}\text { Bacteria } \\
\text { concentration }\end{array}$ & Stab scalpel & Suture & Needle holder \\
\hline \multirow[t]{3}{*}{0 min (sham) } & Low & +++ & ++- & +++ \\
\hline & Medium & +++ & +++ & +++ \\
\hline & High & +++ & +++ & +++ \\
\hline \multirow[t]{4}{*}{$2 \mathrm{~min}$} & None & -- & -- & -- \\
\hline & Low & -- &.- & +++ \\
\hline & Medium & -- & -- & +++ \\
\hline & High & +- & - - - & +++ \\
\hline \multirow[t]{4}{*}{$5 \mathrm{~min}$} & None & -- & -- & -- \\
\hline & Low & -- & -- & $-\cdots$ \\
\hline & Medium & -- & -- & +++ \\
\hline & High & -- & $-\cdots$ & +++ \\
\hline \multirow[t]{4}{*}{$15 \mathrm{~min}$} & None & -- & -- & - \\
\hline & Low & -- & -- & -- \\
\hline & Medium & -- & -- & +++ \\
\hline & High & $-\ldots$ & $-\ldots$ & +++ \\
\hline
\end{tabular}




\subsection{Experiment 3 - Water Mold Testing}

The second part of the hypothesis was to test the efficacy of UV radiation to disinfect tools exposed to a water mold. There was no growth of S. parasitica on any of the agar plates exposed to UV light. Mycelium growth was observed on all three of the sham control plates after $1 \mathrm{~d}$ of incubation. The forceps-agar pinch test did not show any growth in the UV-treated samples after either 5 or $10 \mathrm{~d}$ of incubation. However, growth was observed in only two of the three sham control groups after $2 \mathrm{~d}$ of incubation, and at $10 \mathrm{~d}$ there was no change (Table 5).

Table 5. The presence/absence of the water mold applied to the agar plates and forceps exposed to UV radiation for four different durations and incubated for $10 \mathrm{~d}$. The $(+)$ symbol represents growth in samples for each replicate of the test while the $(-)$ represents no growth in samples.

\begin{tabular}{lcc} 
UV radiation duration & Agar-plate method & Forceps-pinch method \\
\hline $0 \min ($ sham $)$ & +++ & ++- \\
$2 \min$ & -- & -- \\
$5 \mathrm{~min}$ & -- & $-\ldots$ \\
$15 \min$ & -- & -- \\
\hline
\end{tabular}

\subsection{Discussion}

The effective management of pathogens during the surgical implantation of tracking devices into fish is critical for the survival and well-being of the test fish. The reduction of surgically transmitted pathogens is essential for ethical treatment of fish as well as to maintain the behavior and ecology of the test fish. Sterilization of surgical instruments is the most effective means to manage pathogens, but is usually not practical in large fisheries studies conducted in the field. As such, disinfection is a more common approach to pathogen management in surgical procedures conducted in the field. However, most of the disinfectants commonly used today in fisheries studies have certain inherent drawbacks, including toxicity, chemical waste disposal, and hazardous material transportation. There is a need to find new and innovative ways to disinfect surgical instruments. This study suggests that UV radiation, in some circumstances, may be a viable disinfection procedure for fisheries studies involving surgery.

In the first of our three experiments, we showed that the high concentrations of bacteria applied to forceps $\left(1.8 \times 10^{11} \mathrm{CFU} / \mathrm{mL}\right.$ to $\left.6.3 \times 10^{12} \mathrm{CFU} / \mathrm{mL}\right)$ were effectively eliminated using $\mathrm{UV}$ radiation in dose durations between 2 and $15 \mathrm{~min}$. These bacteria represented the pathogens that cause furunculosis (A. salmonicida), coldwater disease (F. psychrophilum), and bacterial kidney disease ( $R$. salmoninarum), three common diseases of juvenile Pacific salmonids. For the bacteria that caused furunculosis and coldwater disease, our tests showed that they were killed with UV radiation at low $\left(1.8 \times 10^{7} \mathrm{CFU} / \mathrm{mL}\right.$ to $\left.5.8 \times 10^{7} \mathrm{CFU} / \mathrm{mL}\right)$ and medium $\left(1.8 \times 10^{9} \mathrm{CFU} / \mathrm{mL}\right.$ to $\left.5.8 \times 10^{9} \mathrm{CFU} / \mathrm{mL}\right)$ concentrations; this conclusion is based on the fact that the bacteria was able to grow at these concentrations on forceps in our 
sham tests but then evidenced no growth in the UV-treated samples. Even though there was not consistent observable growth of $R$. salmoninarum on the forceps following UV treatment in the tests using low $\left(6.3 \times 10^{8} \mathrm{CFU} / \mathrm{mL}\right)$ or medium $\left(6.3 \times 10^{10} \mathrm{CFU} / \mathrm{mL}\right)$ bacteria concentrations, we cannot conclude with absolute certainty that the UV radiation was the reason for no bacteria growth because the sham tests were not reliable. This could be because the lack of growth in the $R$. salmoninarum sham tests at the low and medium concentrations was due to the difficulty associated with culturing this bacteria, requiring up to a month of incubation time to reach a population threshold where the bacteria is visible to our counting method. In each replicate, where $R$. salmoninarum was grown in a sham test, it was effectively eliminated using the UV treatment. The hypothesis is that if $R$. salmoninarum are eliminated at high concentrations, it is likely that it would be eliminated at low concentrations. Further, even the densities of organisms present in the low-concentration exposures in this study are likely much higher than levels found in a river or fish-tagging site. For example, McKibben and Pascho (1999) found tanks holding Chinook salmon infected with $R$. salmoninarum contained only $1.8 \times 10^{3} \mathrm{CFU} / \mathrm{mL}$. This level is much lower than the lowest level of $R$. salmoninarum to which surgical tools were exposed in this study $\left(6.28 \times 10^{8} \mathrm{CFU} / \mathrm{mL}\right)$. Consequently, even with the lack of conclusive finding in the low and medium concentrations, our results give us confidence that the UV radiation is able to kill $R$. salmoninarum at concentrations that may be disease causing in juvenile salmonids.

In the second experiment, it was shown that $A$. salmonicida (furunculosis) was killed with UV radiation of duration doses of 5 and $15 \mathrm{~min}$ all of the time on suture material and stab scalpels, but inconsistently on needle holders. For the suture test, only two of the three low-concentration sham controls grew. However, because all other sham controls in the medium and high concentrations did grow and there was no growth in any of the UV radiation treated samples, it can be said that UV radiation was effective at disinfecting the suture. A 2-min treatment with UV radiation was not always effective at killing high concentrations of bacteria on the stab scalpels but worked on the suture material.

Concentrations of bacteria used in this experiment ranged from $1.4 \times 10^{4} \mathrm{CFU} / \mathrm{mL}$ to $5.9 \times 10^{11} \mathrm{CFU} / \mathrm{mL}$. The hypothesis for the inconsistent results on the stab scalpels (at 2-min treatment) and needle holders (at all treatments) is that these surgical tools have irregular and hidden surfaces that can harbor bacteria, making these surfaces inaccessible to the UV radiation. Other researchers have found that UV light can be ineffective at killing microbes in dental tools that are tubular or have irregular surfaces (Eakle et al. 1986). The pathogen must be "visible" to the UV system for the UV system to be an effective disinfectant. Due to these hidden surfaces, the UV system is likely an inferior method with which to disinfect surgical tools like needle holders that have overlapping joints or stab scalpels that have a space within the handle where the blades are inserted. Although our tests showed that bacteria was not able to grow on suture material after UV treatment of durations of 2 to $15 \mathrm{~min}$, the location where the suture strand is attached to the needle may be an area of concern for harboring bacteria or other pathogens. In addition, a buildup of organic or inorganic debris can shield organisms from exposure to UV light. Therefore, tools should be cleaned to remove debris prior to sterilization or disinfection (Rutala et al. 2008).

In the third experiment, we showed that forceps exposed to water mold were effectively disinfected when treated for 2 to $15 \mathrm{~min}$ with UV radiation. However, as in the experiment with $R$. salmoninarum, one of the three sham tests failed to grow the water mold. Therefore, these findings must be interpreted with caution. We are encouraged, however, that in the agar-plate method where there was growth of the water mold in all three sham replicates, the UV system effectively killed the water mold at UV radiation durations between 2 and $15 \mathrm{~min}$. 
The collective finding of this study is that exposure to UV light appears to be a viable technique for disinfecting at least some tools used to implant transmitters into fish on the selected three bacteria and one water mold. Forceps and suture material, which were fairly smooth and did not harbor pathogens in areas inaccessible to the UV radiation, were effectively disinfected with UV radiation. However, those tools that had overlapping or complex parts presented areas that the UV radiation was not able to reach. We recommend that other methods be used to disinfect or sterilize these tools. One rapid, nonchemical method would be use of a hot bead device. These devices heat small glass beads to $240-270^{\circ} \mathrm{C}$ and can disinfect tools in as few as $20 \mathrm{~s}$ (www.finesciencetools.com).

There are many problems with determining sterilization versus disinfection. Sterile means "to have zero organisms survive"; however, the sterilizer testing process calls for a sterility assurance level (SAL) of $10^{-6}$ (FDA 1993, p.05). This is measured as a probability of sterility for each type of item to be sterilized and is the $\log _{10}$ number of the probability of a survivor on a single item (FDA 1993). A SAL of $10^{-6}$ is the level used most commonly for sterile tools in the United States (Rutala et al. 2008). The U.S. Food and Drug Administration (FDA) has approved neither UV nor hot bead devices as instruments for sterilization. .No single standard has been established in proving a UV system to be a sterilizer nor are any UV units FDA-registered sterilizers. Hot bead sterilizers are acceptable for sterilization in veterinary medicine (NRC 2011) but, like UV, are not FDA registered. The FDA governs chemical sterilants, high-level disinfectants, and sterilization equipment such as autoclaves and dry heat ovens. The FDA has registered sterilizers that use steam, dry heat, and gas plasma. Unfortunately, all three sterilizer types require a long time to sterilize tools. For a device or chemical to be certified as a sterilizer, it must be able to kill the most resistant organism for the specific sterilization process being tested. Traditional devices such as steam sterilizers are most commonly tested using Geobacillus stearothermophilus in the spore life stage, which can take 1 to $2 \mathrm{~min}$ at $121^{\circ} \mathrm{C}$ to be deactivated because the organism is heat resistant. The UV system tested in our experiments was effective at deactivating spores of G. stearothermophilus (ATCC $7953 ; 3.1 \times 10^{5}$ spores/unit) at a treatment duration of $5 \mathrm{~min}$ (unpublished data)

Future work should be done to establish the most resistant microorganism to UV radiation. thus working toward FDA certification. Additional future research is needed to determine if suture tensile strength is affected by UV light over time. If exposure to UV radiation weakens sutures substantially, then incisions may not stay closed, leading to poor healing and tag expulsion, which may lead to bias in the results of telemetry studies.

The UV system may not be suitable under all circumstances. The UV apparatus requires an external power source, so tagging in field locations would require a generator or battery and power inverter. The UV light sources need adequate safety mechanisms to prevent exposure of people to light during use. Also, the bulbs lose power over time. Based on information from Millipore, they would need to be replaced every $4000 \mathrm{~h}$ of use.

\subsection{Conclusion}

UV radiation was effective at disinfecting forceps exposed to three bacteria and for all UV radiation durations. Even though we did not see any growth in the low- and medium-concentration sham controls for BKD (R. salmoninarum), we did have growth in all the high-concentration sham controls and no 
growth in UV radiation-treated samples. Thus, we can conclude that UV radiation is effective at disinfecting forceps exposed to BKD. UV radiation was also effective at disinfecting sutures and stab scalpels, but we did have growth in one of the 2-min treatments for stab scalpels. UV radiation is not an adequate means of disinfection for needle holders due to the growth present at all durations of UV radiation exposure. The water mold was also disinfected at all durations of UV radiation exposure. Due to the growth seen in testing with stab scalpels at $2 \mathrm{~min}$, we recommend exposures of 5 min to UV radiation to adequately disinfect forceps, sutures, and stab scalpels.

\subsection{References}

Baras E and JP Lagardére. 1995. Fish telemetry in aquaculture: review and perspectives. Aquaculture International 3:77-102.

Bégout Anras ML, RA Bodaly, and R McNicol. 1998. Use of an acoustic beam actograph to assess the effects of external tagging procedure on lake whitefish swimming activity. Transaction of the American Fisheries Society 127:329-335.

Bohrerova Z, H Shemer, R Lantis, CA Impellitteri, and KG Linden. 2008. Comparative disinfection efficiency of pulsed and continuous-wave UV irradiation technologies. Water Research 42:2075-2982.

Bridger CJ and RK Booth. 2003. The effects of biotelemetry transmitter presence and attachment procedures on fish physiology and behavior. Review in Fisheries Science 11(1):13-34.

Brown RS, RA Harnish, KM Carter, JW Boyd, and KA Deters. 2010. An evaluation of the maximum tag burden for implantation of acoustic transmitters in juvenile Chinook salmon. North American Journal of Fisheries Management 30:499-505.

Eakle SW, RT Kao, M Gordon, and RB Pelzner. 1986. Microbiological assessment of ultraviolet sterilization of dental handpieces. Clinical Preventive Dentistry 8(2):10-14.

FDA. 1993. Guidance on premarket notification [510 (k)] submissions for sterilizers intended for use in health care facilities. Document No. 833, Infection Control Devices Branch, Division of General and Restorative Devices, Office of Device Evaluation, Center for Devices and Radiological Health, U.S. Food and Drug Administration, Washington, D.C. Available from http://www.fda.gov/downloads/ MedicalDevices/DeviceRegulationandGuidance/GuidanceDocuments/UCM081341.pdf (November 2011).

Giese N and J Darby. 2000. Sensitivity of microorganisms to different wavelengths of UV light: implications on modeling of medium pressure UV systems. Water Research 34:4007-4013.

Gurevich I, R Dubin, and BA Cunha. 1996. Dental instrument and device sterilization and disinfection practices. Journal of Hospital Infection 32:295-304.

Liltved H and B Landfald. 2000. Effects of high intensity light on ultraviolet-irradiated and nonirradiated fish pathogenic bacteria. Water Research 34(2):481-486. 
Liltved H, H Hektoen, and H Efraimsen. 1995. Inactivation of bacterial and viral fish pathogens by ozonation or UV irradiation in water of different salinity. Aquacultural Engineering 14:107-122.

Liltved H, C Vogelsang, I Modahl, and BH Dannevig. 2006. High resistance of fish pathogenic viruses to UV irradiation and ozonated seawater. Aquacultural Engineering 34:72-82.

Martin SB, C Dunn, JD Freihaut, WP Bahnfleth, J Lau, and A Nedeljkovic-Davidovic. 2008. Ultraviolet germicidal irradiation: Current best practices. ASHRAE Journal 50(8):28-30, 32-34, 36.

McKibben CL and RJ Pascho. 1999. Shedding of Renibacterium salmoninarum by infected Chinook salmon Oncorhynchus tshawytscha. Diseases of Aquatic Organisms 38:75-79.

McMichael GA, MB Eppard, TJ Carlson, JA Carter, BD Ebberts, RS Brown, M Weiland, GR Ploskey, RA Harnish, and ZD Deng. 2010. The Juvenile Salmon Acoustic Telemetry System: A new tool. Fisheries 35(1):9-22.

National Research Council. 2011. Guide for the Care and Use of Laboratory Animals. 8th edition. Committee for the Update of the Guide for the Care and Use of Laboratory Animals, National Research Council, The National Academies Press, Washington, D.C. Available from http://www.aaalac.org/resources/Guide_2011.pdf(February 2012).

Rutala WA, DJ Weber, and the Healthcare Infection Control Practices Advisory Committee. 2008. Guideline for Disinfection and Sterilization in Healthcare Facilities. Centers for Disease Control and Prevention, U.S. Department of Health and Human Services, Atlanta, Georgia. Available from http://www.cdc.gov/hicpac/pdf/guidelines/Disinfection_Nov_2008.pdf (November 2011).

Sharrer MJ, ST Summerfelt, GL Bullock, LE Gleason, and J TaeuberJ. 2005. Inactivation of bacteria using ultraviolet irradiation in a recirculating salmonid culture system. Aquacultural Engineering $33: 135-149$.

Summerfelt ST. 2003. Ozonation and UV irradiation — an introduction and examples of current applications. Aquacultural Engineering 28:21-36.

Wagner GN, SJ Cooke, RS Brown, and KA Deters. 2011. A review of surgical implantation techniques for transmitters and other electronic tags in fish. Reviews in Fish Biology and Fisheries 21:71-81.

Wedemeyer GA. 1996. Physiology of Fish in Intensive Culture Systems. Chapman \& Hall, New York. 


\section{Appendix A}

\section{Optical Densities}





\section{Appendix A}

\section{Optical Densities}

Table A.1. Optical densities $\left(\mathrm{OD}_{600}\right)$ for forceps exposed to $A$. salmonicida.

\begin{tabular}{lccccc}
\hline $\begin{array}{l}\text { UV radiation } \\
\text { duration }\end{array}$ & $\begin{array}{c}\text { Bacteria } \\
\text { concentration }\end{array}$ & Mean \pm SD & Replicate 1 & Replicate 2 & Replicate 3 \\
\hline 0 min (sham) & Low & $0.04 \pm 0.02$ & 0.03 & 0.06 & 0.03 \\
& Medium & $0.03 \pm 0.02$ & 0.05 & 0.02 & 0.02 \\
& High & $0.03 \pm 0.01$ & 0.02 & 0.04 & 0.03 \\
\hline 2 min & None & $0.00 \pm 0.00$ & 0.00 & 0.00 & 0.00 \\
& Low & $0.00 \pm 0.00$ & 0.00 & 0.00 & 0.00 \\
& Medium & $0.00 \pm 0.00$ & 0.00 & 0.00 & 0.00 \\
& High & $0.00 \pm 0.00$ & 0.00 & 0.00 & 0.00 \\
\hline 5 min & None & $0.00 \pm 0.00$ & 0.00 & 0.00 & 0.00 \\
& Low & $0.00 \pm 0.00$ & 0.00 & 0.00 & 0.00 \\
& Medium & $0.00 \pm 0.00$ & 0.00 & 0.00 & 0.00 \\
& High & $0.00 \pm 0.00$ & 0.00 & 0.00 & 0.00 \\
\hline min & None & $0.00 \pm 0.00$ & 0.00 & 0.00 & 0.00 \\
& Low & $0.00 \pm 0.00$ & 0.00 & 0.00 & 0.00 \\
& Medium & $0.00 \pm 0.00$ & 0.00 & 0.00 & 0.00 \\
& High & $0.00 \pm 0.00$ & 0.00 & 0.00 & 0.00 \\
\hline
\end{tabular}


Table A.2. Optical densities $\left(\mathrm{OD}_{600}\right)$ for forceps exposed to F. psychrophilum.

\begin{tabular}{lccccc}
\hline $\begin{array}{l}\text { UV radiation } \\
\text { duration }\end{array}$ & $\begin{array}{c}\text { Bacteria } \\
\text { concentration }\end{array}$ & Mean \pm SD & Replicate 1 & Replicate 2 & Replicate 3 \\
\hline 0 min (sham) & Low & $0.03 \pm 0.00$ & 0.02 & 0.02 & 0.02 \\
& Medium & $0.03 \pm 0.01$ & 0.02 & 0.04 & 0.04 \\
& High & $0.05 \pm 0.01$ & 0.04 & 0.06 & 0.05 \\
\hline 2 min & None & $0.00 \pm 0.00$ & 0.00 & 0.00 & 0.00 \\
& Low & $0.00 \pm 0.00$ & 0.00 & 0.00 & 0.00 \\
& Medium & $0.00 \pm 0.00$ & 0.00 & 0.00 & 0.00 \\
& High & $0.00 \pm 0.00$ & 0.00 & 0.00 & 0.00 \\
\hline 5 min & None & $0.00 \pm 0.00$ & 0.00 & 0.00 & 0.00 \\
& Low & $0.00 \pm 0.00$ & 0.00 & 0.00 & 0.00 \\
& Medium & $0.00 \pm 0.00$ & 0.00 & 0.00 & 0.00 \\
& High & $0.00 \pm 0.00$ & 0.00 & 0.00 & 0.00 \\
\hline min & None & $0.00 \pm 0.00$ & 0.00 & 0.00 & 0.00 \\
& Low & $0.00 \pm 0.00$ & 0.00 & 0.00 & 0.00 \\
& Medium & $0.00 \pm 0.00$ & 0.00 & 0.00 & 0.00 \\
& High & $0.00 \pm 0.00$ & 0.00 & 0.00 & 0.00 \\
\hline
\end{tabular}


Table A.3. Optical densities $\left(\mathrm{OD}_{600}\right)$ for forceps exposed to $R$. salmoninarum.

\begin{tabular}{|c|c|c|c|c|c|c|c|}
\hline $\begin{array}{l}\text { UV radiation } \\
\text { duration }\end{array}$ & $\begin{array}{c}\text { Bacteria } \\
\text { concentration }\end{array}$ & Mean \pm SD & Replicate 1 & Replicate 2 & Replicate 3 & Replicate 4 & Replicate 5 \\
\hline \multirow[t]{3}{*}{0 min (sham) } & Low & $0.00 \pm 0.00$ & 0.00 & 0.00 & 0.00 & 0.00 & 0.00 \\
\hline & Medium & $0.02 \pm 0.05$ & 0.10 & 0.00 & 0.00 & 0.00 & 0.00 \\
\hline & High & $0.18 \pm 0.05$ & 0.18 & 0.18 & 0.26 & 0.19 & 0.11 \\
\hline \multirow[t]{4}{*}{$2 \mathrm{~min}$} & None & $0.00 \pm 0.00$ & 0.00 & 0.00 & 0.00 & 0.00 & 0.00 \\
\hline & Low & $0.00 \pm 0.00$ & 0.00 & 0.00 & 0.00 & 0.00 & 0.00 \\
\hline & Medium & $0.00 \pm 0.00$ & 0.00 & 0.00 & 0.00 & 0.00 & 0.00 \\
\hline & High & $0.00 \pm 0.00$ & 0.00 & 0.00 & 0.00 & 0.00 & 0.00 \\
\hline \multirow[t]{4}{*}{$5 \min$} & None & $0.00 \pm 0.00$ & 0.00 & 0.00 & 0.00 & 0.00 & 0.00 \\
\hline & Low & $0.00 \pm 0.01$ & 0.00 & 0.00 & 0.00 & 0.00 & 0.00 \\
\hline & Medium & $0.00 \pm 0.00$ & 0.00 & 0.02 & 0.00 & 0.00 & 0.00 \\
\hline & High & $0.00 \pm 0.00$ & 0.00 & 0.00 & 0.00 & 0.00 & 0.00 \\
\hline \multirow[t]{4}{*}{$15 \mathrm{~min}$} & None & $0.00 \pm 0.00$ & 0.00 & 0.00 & 0.00 & 0.00 & 0.00 \\
\hline & Low & $0.00 \pm 0.00$ & 0.00 & 0.00 & 0.00 & 0.00 & 0.00 \\
\hline & Medium & $0.00 \pm 0.00$ & 0.00 & 0.00 & 0.00 & 0.00 & 0.00 \\
\hline & High & $0.03 \pm 0.07$ & 0.00 & 0.00 & 0.00 & 0.17 & 0.00 \\
\hline
\end{tabular}


Table A.4. Optical densities $\left(\mathrm{OD}_{600}\right)$ for stab scalpels exposed to $A$. salmonicida

\begin{tabular}{lccccc}
\hline $\begin{array}{l}\text { UV radiation } \\
\text { duration }\end{array}$ & Bacteria & Mean \pm SD & Replicate 1 & Replicate 2 & Replicate 3 \\
\hline 0 min (sham) & Low & $0.03 \pm 0.03$ & 0.01 & 0.06 & 0.02 \\
& Medium & $0.03 \pm 0.02$ & 0.05 & 0.03 & 0.02 \\
& High & $0.02 \pm 0.01$ & 0.01 & 0.03 & 0.03 \\
\hline 2 min & None & $0.00 \pm 0.00$ & 0.00 & 0.00 & 0.00 \\
& Low & $0.00 \pm 0.00$ & 0.00 & 0.00 & 0.00 \\
& Medium & $0.00 \pm 0.00$ & 0.00 & 0.00 & 0.00 \\
& High & $0.01 \pm 0.01$ & 0.00 & 0.02 & 0.00 \\
\hline 5 min & None & $0.00 \pm 0.00$ & 0.00 & 0.00 & 0.00 \\
& Low & $0.00 \pm 0.00$ & 0.00 & 0.00 & 0.00 \\
& Medium & $0.00 \pm 0.00$ & 0.00 & 0.00 & 0.00 \\
& High & $0.00 \pm 0.00$ & 0.00 & 0.00 & 0.00 \\
\hline 5 min & None & $0.00 \pm 0.00$ & 0.00 & 0.00 & 0.00 \\
& Low & $0.00 \pm 0.00$ & 0.00 & 0.00 & 0.00 \\
& Medium & $0.00 \pm 0.00$ & 0.00 & 0.00 & 0.00 \\
& High & $0.00 \pm 0.00$ & 0.00 & 0.00 & 0.00 \\
\hline
\end{tabular}


Table A.5. Optical densities $\left(\mathrm{OD}_{600}\right)$ for sutures exposed to A. salmonicida

\begin{tabular}{lccccc}
\hline $\begin{array}{l}\text { UV radiation } \\
\text { duration }\end{array}$ & $\begin{array}{c}\text { Bacteria } \\
\text { concentration }\end{array}$ & Mean \pm SD & Replicate 1 & Replicate 2 & Replicate 3 \\
\hline 0 min (sham) & Low & $0.01 \pm 0.01$ & 0.02 & 0.01 & 0.00 \\
& Medium & $0.02 \pm 0.01$ & 0.03 & 0.02 & 0.01 \\
& High & $0.01 \pm 0.00$ & 0.01 & 0.02 & 0.01 \\
\hline 2 min & None & $0.00 \pm 0.00$ & 0.00 & 0.00 & 0.00 \\
& Low & $0.00 \pm 0.00$ & 0.00 & 0.00 & 0.00 \\
& Medium & $0.00 \pm 0.00$ & 0.00 & 0.00 & 0.00 \\
& High & $0.01 \pm 0.01$ & 0.00 & 0.00 & 0.00 \\
\hline 5 min & None & $0.00 \pm 0.00$ & 0.00 & 0.00 & 0.00 \\
& Low & $0.00 \pm 0.00$ & 0.00 & 0.00 & 0.00 \\
& Medium & $0.00 \pm 0.00$ & 0.00 & 0.00 & 0.00 \\
& High & $0.00 \pm 0.00$ & 0.00 & 0.00 & 0.00 \\
\hline 15 min & None & $0.00 \pm 0.00$ & 0.00 & 0.00 & 0.00 \\
& Low & $0.00 \pm 0.00$ & 0.00 & 0.00 & 0.00 \\
& Medium & $0.00 \pm 0.00$ & 0.00 & 0.00 & 0.00 \\
& High & $0.00 \pm 0.00$ & 0.00 & 0.00 & 0.00 \\
\hline
\end{tabular}


Table A.6. Optical densities $\left(\mathrm{OD}_{600}\right)$ for needle holders exposed to A. salmonicida

\begin{tabular}{lccccc}
\hline $\begin{array}{l}\text { UV radiation } \\
\text { duration }\end{array}$ & $\begin{array}{c}\text { Bacteria } \\
\text { concentration }\end{array}$ & Mean \pm SD & Replicate 1 & Replicate 2 & Replicate 3 \\
\hline 0 min (sham) & Low & $0.01 \pm 0.00$ & 0.01 & 0.01 & 0.01 \\
& Medium & $0.01 \pm 0.00$ & 0.01 & 0.01 & 0.01 \\
& High & $0.02 \pm 0.02$ & 0.01 & 0.05 & 0.01 \\
\hline 2 min & None & $0.00 \pm 0.00$ & 0.00 & 0.00 & 0.00 \\
& Low & $0.00 \pm 0.01$ & 0.00 & 0.00 & 0.01 \\
& Medium & $0.01 \pm 0.00$ & 0.01 & 0.01 & 0.01 \\
& High & $0.01 \pm 0.00$ & 0.01 & 0.01 & 0.01 \\
\hline 5 min & None & $0.00 \pm 0.00$ & 0.00 & 0.00 & 0.00 \\
& Low & $0.00 \pm 0.00$ & 0.00 & 0.00 & 0.00 \\
& Medium & $0.01 \pm 0.00$ & 0.01 & 0.01 & 0.01 \\
& High & $0.02 \pm 0.02$ & 0.04 & 0.01 & 0.01 \\
\hline min & None & $0.00 \pm 0.00$ & 0.00 & 0.00 & 0.00 \\
& Low & $0.00 \pm 0.00$ & 0.00 & 0.00 & 0.00 \\
& Medium & $0.01 \pm 0.01$ & 0.01 & 0.00 & 0.01 \\
& High & $0.01 \pm 0.00$ & 0.01 & 0.01 & 0.01 \\
\hline
\end{tabular}




\section{Appendix B}

\section{Ultraviolet Dose Measurements}





\section{Appendix B}

\section{Ultraviolet Dose Measurements}

Table B.1. Forceps dose measurements for each replicate of the UV light exposure experiments. The pathogen used for the exposure was A. salmonicida.

\begin{tabular}{|c|c|c|c|c|c|}
\hline \multicolumn{6}{|c|}{ A. salmonicida } \\
\hline $\begin{array}{l}\text { UV radiation } \\
\text { duration }\end{array}$ & & Mean \pm SD & Test 1 & Test 2 & Test 3 \\
\hline \multirow[t]{2}{*}{$2 \mathrm{~min}$} & Dose $\mathrm{mJ} / \mathrm{cm}^{2}$ & $118.42 \pm 5.53$ & 119.84 & 123.11 & 112.32 \\
\hline & Irradiance $\mathrm{mW} / \mathrm{cm}^{2}$ & $1.15 \pm 0.07$ & 1.18 & 1.20 & 1.08 \\
\hline \multirow[t]{2}{*}{$5 \mathrm{~min}$} & Dose $\mathrm{mJ} / \mathrm{cm}^{2}$ & $331.39 \pm 1.70$ & 333.20 & 329.84 & 331.11 \\
\hline & Irradiance $\mathrm{mW} / \mathrm{cm}^{2}$ & $1.23 \pm 0.01$ & 1.23 & 1.22 & 1.24 \\
\hline \multirow[t]{2}{*}{$15 \mathrm{~min}$} & Dose $\mathrm{mJ} / \mathrm{cm}^{2}$ & $1007.21 \pm 33.97$ & 982.88 & 1046.02 & 992.73 \\
\hline & Irradiance $\mathrm{mW} / \mathrm{cm}^{2}$ & $1.19 \pm 0.04$ & 1.17 & 1.23 & 1.16 \\
\hline
\end{tabular}

Table B.2. Forceps dose measurements for each replicate of the UV light exposure experiments. The pathogen used for the exposure was $F$. psychrophilum.

\begin{tabular}{|c|c|c|c|c|c|}
\hline \multicolumn{6}{|c|}{ F.psychrophilum } \\
\hline $\begin{array}{l}\text { UV radiation } \\
\text { duration }\end{array}$ & & Mean \pm SD & Test 1 & Test 2 & Test 3 \\
\hline \multirow[t]{2}{*}{$2 \min$} & Dose $\mathrm{mJ} / \mathrm{cm}^{2}$ & $118.57 \pm 2.14$ & 120.05 & 116.11 & 119.54 \\
\hline & Irradiance $\mathrm{mW} / \mathrm{cm}^{2}$ & $1.16 \pm 0.04$ & 1.20 & 1.12 & 1.15 \\
\hline \multirow[t]{2}{*}{$5 \mathrm{~min}$} & Dose $\mathrm{mJ} / \mathrm{cm}^{2}$ & $318.73 \pm 8.44$ & 310.35 & 327.23 & 318.60 \\
\hline & Irradiance $\mathrm{mW} / \mathrm{cm}^{2}$ & $1.19 \pm 0.03$ & 1.16 & 1.22 & 1.18 \\
\hline \multirow[t]{2}{*}{$15 \mathrm{~min}$} & Dose $\mathrm{mJ} / \mathrm{cm}^{2}$ & $1036.56 \pm 21.98$ & 1036.13 & 1014.80 & 1058.76 \\
\hline & Irradiance $\mathrm{mW} / \mathrm{cm}^{2}$ & $1.22 \pm 0.02$ & 1.22 & 1.21 & 1.24 \\
\hline
\end{tabular}


Table B.3. Forceps dose measurements for each replicate of the UV light exposure experiments. The pathogen used for the exposure was $R$. salmoninarum.

\begin{tabular}{|c|c|c|c|c|c|c|c|}
\hline \multicolumn{8}{|c|}{ R. salmoninarum } \\
\hline $\begin{array}{l}\text { UV radiation } \\
\text { duration }\end{array}$ & & Mean \pm SD & Test 1 & Test 2 & Test 3 & Test 4 & Test 5 \\
\hline \multirow[t]{2}{*}{$2 \min$} & Dose $\mathrm{mJ} / \mathrm{cm}^{2}$ & $121.00 \pm 8.22$ & 119.06 & 115.74 & 116.97 & 117.69 & 135.55 \\
\hline & Irradiance $\mathrm{mW} / \mathrm{cm}^{2}$ & $1.17 \pm 0.03$ & 1.15 & 1.17 & 1.16 & 1.15 & 1.23 \\
\hline \multirow[t]{2}{*}{$5 \mathrm{~min}$} & Dose $\mathrm{mJ} / \mathrm{cm}^{2}$ & $318.54 \pm 14.95$ & 299.47 & 317.81 & 335.23 & 309.01 & 331.19 \\
\hline & Irradiance $\mathrm{mW} / \mathrm{cm}^{2}$ & $1.18 \pm 0.04$ & 1.13 & 1.19 & 1.20 & 1.14 & 1.23 \\
\hline \multirow[t]{2}{*}{$15 \mathrm{~min}$} & Dose $\mathrm{mJ} / \mathrm{cm}^{2}$ & $1025.41 \pm 18.80$ & 1028.21 & 1036.64 & 994.03 & 1025.57 & 1042.57 \\
\hline & Irradiance $\mathrm{mW} / \mathrm{cm}^{2}$ & $1.23 \pm 0.01$ & 1.22 & 1.24 & 1.22 & 1.22 & 1.24 \\
\hline
\end{tabular}

Table B.4. Forceps dose measurements for the $S$. parasitica UV exposure tests.

\begin{tabular}{lccc}
\hline & S. parasitica & & \\
$\begin{array}{l}\text { UV radiation } \\
\text { duration }\end{array}$ & & Forceps & Agar plates \\
\hline $2 \mathrm{~min}$ & Dose $\mathrm{mJ} / \mathrm{cm}^{2}$ & 120.15 & 121.36 \\
& Irradiance $\mathrm{mW} / \mathrm{cm}^{2}$ & 1.20 & 1.18 \\
& & & \\
& & & \\
& Dose $\mathrm{mJ} / \mathrm{cm}^{2}$ & 326.77 & 358.66 \\
& Irradiance $\mathrm{mW} / \mathrm{cm}^{2}$ & 1.23 & 1.30 \\
& & & 1.3082 .32 \\
& Dose $\mathrm{mJ} / \mathrm{cm}^{2}$ & 1171.43 & 1.26 \\
\hline
\end{tabular}


Table B.5. Stab scalpel dose measurements for each replicate of the UV light exposure experiments.

\begin{tabular}{|c|c|c|c|c|c|}
\hline & & Stab Scalpel & & & \\
\hline $\begin{array}{l}\text { UV radiation } \\
\text { duration }\end{array}$ & & Mean (SD) & Replicate 1 & Replicate 2 & Replicate 3 \\
\hline \multirow[t]{2}{*}{$2 \min$} & Energy $\mathrm{mJ} / \mathrm{cm}^{2}$ & $126.07 \pm 3.97$ & 122.50 & 130.36 & 125.36 \\
\hline & Irradiance $\mathrm{mW} / \mathrm{cm}^{2}$ & $1.22 \pm 0.02$ & 1.21 & 1.24 & 1.21 \\
\hline \multirow[t]{2}{*}{$5 \mathrm{~min}$} & Energy $\mathrm{mJ} / \mathrm{cm}^{2}$ & $332.04 \pm 4.24$ & 336.13 & 332.33 & 327.67 \\
\hline & Irradiance $\mathrm{mW} / \mathrm{cm}^{2}$ & $1.24 \pm 0.02$ & 1.25 & 1.25 & 1.21 \\
\hline \multirow[t]{2}{*}{$15 \mathrm{~min}$} & Energy $\mathrm{mJ} / \mathrm{cm}^{2}$ & $1072.45 \pm 3.21$ & 1071.82 & 1075.93 & 1069.61 \\
\hline & Irradiance $\mathrm{mW} / \mathrm{cm}^{2}$ & $1.27 \pm 0.02$ & 1.27 & 1.28 & 1.24 \\
\hline
\end{tabular}

Table B.6. Suture dose measurements for each replicate of the UV light exposure experiments.

\begin{tabular}{lccccc}
\hline $\begin{array}{l}\text { UV radiation } \\
\text { duration }\end{array}$ & & $\begin{array}{c}\text { Suture } \\
\text { Mean (SD) }\end{array}$ & Replicate 1 & Replicate 2 & Replicate 3 \\
\hline $2 \mathrm{~min}$ & Energy $\mathrm{mJ} / \mathrm{cm}^{2}$ & $124.93 \pm 4.76$ & 120.90 & 130.18 & 123.72 \\
& Irradiance $\mathrm{mW} / \mathrm{cm}^{2}$ & $1.24 \pm 0.05$ & 1.19 & 1.30 & 1.22 \\
& & & & \\
$5 \mathrm{~min}$ & Energy $\mathrm{mJ} / \mathrm{cm}^{2}$ & $341.27 \pm 7.38$ & 333.66 & 348.39 & 341.77 \\
& Irradiance $\mathrm{mW} / \mathrm{cm}^{2}$ & $1.27 \pm 0.01$ & 1.26 & 1.27 & 1.27 \\
& & & & & 1102.56 \\
& & $1082.14 \pm 60.37$ & 1129.65 & 1014.21 & 1.30 \\
\hline
\end{tabular}


Table B.7. Needle holder dose measurements for each replicate of the UV light exposure experiments.

\begin{tabular}{lccccc}
\hline $\begin{array}{l}\text { UV radiation } \\
\text { duration }\end{array}$ & & $\begin{array}{c}\text { Needle holder } \\
\text { Mean (SD) }\end{array}$ & Replicate 1 & Replicate 2 & Replicate 3 \\
\hline $2 \mathrm{~min}$ & Energy $\mathrm{mJ} / \mathrm{cm}^{2}$ & $108.90 \pm 2.75$ & 109.01 & 111.59 & 106.09 \\
& Irradiance $\mathrm{mW} / \mathrm{cm}^{2}$ & $1.08 \pm 0.01$ & 1.07 & 1.09 & 1.08 \\
& & & & \\
$5 \mathrm{~min}$ & Energy $\mathrm{mJ} / \mathrm{cm}^{2}$ & $294.01 \pm 8.57$ & 297.37 & 300.39 & 284.26 \\
& Irradiance $\mathrm{mW} / \mathrm{cm}^{2}$ & $1.09 \pm 0.02$ & 1.08 & 1.12 & 1.08 \\
& & & & \\
$15 \mathrm{~min}$ & Energy $\mathrm{mJ} / \mathrm{cm}^{2}$ & $939.08 \pm 17.47$ & 947.09 & 951.12 & 919.04 \\
& Irradiance $\mathrm{mW} / \mathrm{cm}^{2}$ & $1.11 \pm 0.02$ & 1.13 & 1.12 & 1.09 \\
\hline
\end{tabular}





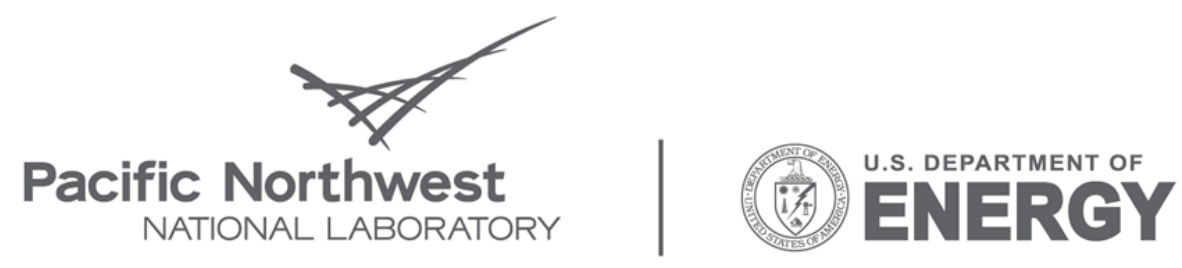

Proudly Operated by Battelle Since 1965

902 Battelle Boulevard

P.O. Box 999

Richland, WA 99352

1-888-375-PNNL (7665)

www.pnl.gov 